\title{
Effect of Information System on Upstream Supply Chain Management Among Supermarkets in Nakuru Town, Kenya
}

\author{
Caroline Mundia ${ }^{1}$, Elton Kipkorir Langat ${ }^{1}$, Steve Lelegwe ${ }^{2}$ \\ ${ }^{1}$ Department of Accounting, Finance and Management Science, Egerton University, Nakuru, Kenya \\ ${ }^{2}$ Department of Education and External studies, University of Nairobi, Nairobi, Kenya \\ Email address: \\ muthcarol@gmail.com (C. Mundia), elmag71@gmail.com (E. K. Langat), slelegwe@gmail.com (S. Lelegwe)
}

\section{To cite this article:}

Caroline Mundia, Elton Kipkorir Langat, Steve Lelegwe. Effect of Information System on Upstream Supply Chain Management Among Supermarkets in Nakuru Town, Kenya. International Journal of Economics, Finance and Management Sciences.

Vol. 3, No. 5, 2015, pp. 535-540. doi: 10.11648/j.ijefm.20150305.24

\begin{abstract}
This study was conducted to find out the effect of Information Systems on Upstream Supply Chain Management. It determined the effect of ERO on Upstream Supply Chain Management and the effect of EDI on Upstream Supply Chain Management among supermarkets within Nakuru town. This study involved all the 9 supermarkets in Nakuru town. The primary data on information systems, enterprise resource planning and upstream supply chain management was collected using structured questionnaires with research items on each of the variables. Collected data was analyzed using a regression analysis to establish the effect of Enterprise Resource Planning and Electronic Data Interchange on Upstream Supply Chain Management. The results of the study will be shown using tables. The study findings revealed that ERP has statistically insignificant effect on Upstream Supply Chain Management while EDI has significant positive effect on Upstream Supply Chain. The recommended that organizations, especially fast moving inventory should take a strategic approach to adoption of information systems concerned with supply chain management.
\end{abstract}

Keywords: Enterprise Resource Planning, Electronic Data Interchange, Upstream Supply Chain Management

\section{Introduction}

\subsection{Background Information}

Organizations are adopting various strategies to ensure they remain competitive in the market. Automation, use of computer aided systems and the use of the internet has become very popular. In the attempt to link up with the suppliers and customers, organizations resort to use of information systems that provide real time link with the stakeholders. Some have resorted to e commerce and e -supply chain management. The success of supply chain depends on the ease of information flow between the organization and the stakeholders (Suppliers and Customers). Information affects all supply chain processes such as inventory forecasts, inventory allocation, and production planning among other operations. An organization can develop its own information system to manage its supply chain operations, instruct an application service provider to develop a customized system or buy an already built one all-together (Giménez and Lourenço, 2005).

Adoption of information system is not unique in the global platform. In the western part of the world like in the US for instance, adoption of information system strategies in supply chain operations can be traced back to 1980s (Maru and Pesce, 2000). The Pan African Development Information System reports that various organizations in Africa already use information systems in various business operations such as marketing, finance and accounting and supply chain. In Kenya, the use of information systems in supply chain has become a popular practice especially among large scale retailers. Nakumatt and Tuskys supermarkets are currently using and integrated information system for purchasing and inventory management operations (Ali-Dinar, 2014 ).

\subsection{Research Objectives}

i. To determine the impact of Enterprise Resource Planning on Upstream Supply Chain Management

ii. To investigate the effects of Electronic Data Interchange on Upstream Supply Chain Management

\subsection{Research Hypotheses}

$\mathrm{Ho}_{1}$ : Enterprise Resource Planning does not have 
significant effect on Upstream Supply Chain Management

$\mathrm{Ho}_{2}$ : Electronic Data Interchange does not have significant effect on Upstream Supply Chain Management

\section{Literature Review}

\subsection{Information Systems}

According to Motwani et al. (2000), automation of supply chain management is critical. Companies need to invest considerable amount of money to redesign internal organizational and technical processes, changing traditional and fundamental product distribution channels and customer service procedure and training staff to achieve IT-enabled supply chain. There are supply chain management software that can be used by the any organization. Whichever software an organization adopts, a supply chain management system adopted by an organization should be able to achieve the following objectives: reduction of production costs, lead time, reduction of inventory and shortfall, transportation costs, purchase costs, improvement of supplier evaluation and selection, improvement of service levels and improvement of cooperation. Organizations adopt various communication technologies. The commonly used communication technologies include: Electronic Data Interchange (EDI), Enterprise Resource Planning (ERP) (Buxmann et al, 2004).

\subsubsection{Enterprise Resource Planning (ERP)}

ERP majorly support inbound oriented functions. Most supply chain software providers provide systems that are based on ERP systems to carry out execution of planned tasks. According to Nemati and Mangaladurai (2013), ERP can be used by an organization to improve its supply chain network. In addition, ERP can be used to minimize delays in the supply chain through coordinated execution of all activities in the supply chain ensuring timely delivery across the entire supply chain, enhanced collaboration among the supply chain partners and control of suppliers operations and achieve reduced cost of operations in the supply chain through improved inventory management and enhanced response time thus reducing wastages in the supply chain network.

According to Segura (2013), ERP system coordinates operations of the organization and its relationship with its suppliers and customers. He developed an ERP framework that explains the operations of an ERP system as shown in figure 2.1.

According to Umble et al (2003), implementation of ERP system follows ten steps. The first step involves a review of the pre-implementation process to establish the current state of the information systems in the organization. The second stage involves installation and test of new hardware to ensure reliability of the systems. The third stage involves installation of software and pilot testing of the new systems to ensure the systems are correctly installed. Once the systems are installed and correctly working, what follows is training of employees on the new system on how it runs and on the conference room pilot. The sixth stage involves building security systems and designing the necessary access codes and systems. The next stage involves establishing data bridges to ensure data shared through the system is accurate. Once this is done, the next stage involves documentation of policies and procedures to guide the operations of the system. The ninth stage is about introducing the entire organization in terms with the newly adopted system. The last stage then involves celebration of the success already achieved. It is important to note that the system requires continuous improvement to ensure it adapts to technological and market changes.

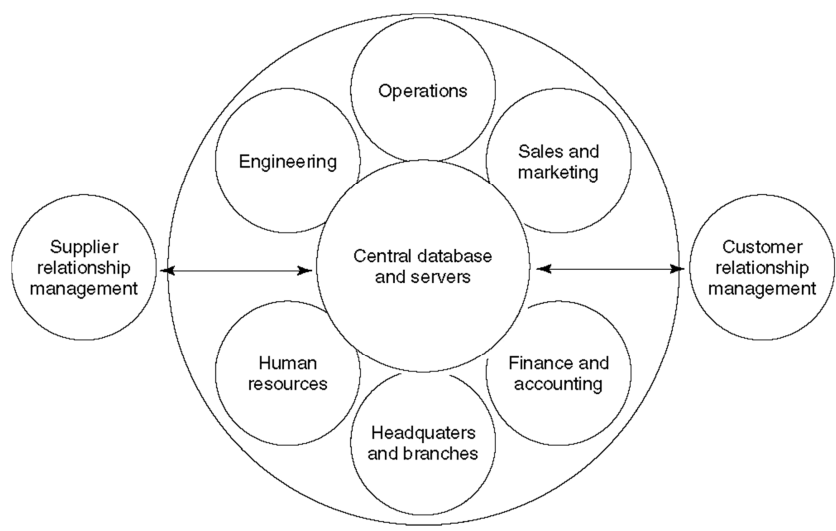

Figure 2.1. ERP framework. Source: (Segura, 2013).

However, not all ERP systems are successfully implemented. Umble et al (2003) and Fui-Hoonnah and Delgado (2006) identified reasons which may lead to failure of an ERP system. The first two reasons are; setting strategic ERP systems that that are not clearly and specifically defined and lack of total commitment by the top management especially in fostering organizational change required for an ERP system. The third reason for failure is poor implementation and management of ERP projects. This is common especially where achievable schedules are not developed, where there is mismatch the business and the ERP system developed and the attempt to automate the systems have failed. Other problems include; lack of commitment to change and poor organizational culture, poor selection of management team, inadequate training and development of the implementation team, use of inaccurate data and information in the system, adoption of poor evaluation process, poor resolution of organizational issues and problems that may influence implementation of ERP and failure to resolve technical problems that may arise in the process.

ERP if well implemented is associated with a number of benefits to the organization. OíLeary (2004) categorized these benefits into tangible and intangible benefits. Tangible benefits include; inventory reduction, personnel reduction, productivity improvements, improved order management, reduced financial close cycle, IT Cost Reduction, procurement cost reduction, cash management improvement, revenue/profit increases, transportation/logistics cost reductions, maintenance and maintenance cost reductions and on time delivery. Intangible benefits on the other hand include; improved information visibility, improved processes, enhanced customer responsiveness, reduced costs, easier standardization, flexibility in the purchasing operations and 
improved supply chain business performance.

\subsubsection{Electronic Data Interchange (EDI)}

According to Swatman and Swatman (1991), EDI is the exchange of data between computers systems initiated using standard document formats known as transaction sets used in routine transition of large volumes of repetitive documents. Use of EDI is associated with reduced cost of administration and improved speed and accuracy in data management. It enables organizations to send and receive standardized business communications more quickly, flexibly, cheaply and with greater security and accuracy than is possible with conventional postal services. EDI is a standard method of transferring commercial information between computers. EDI contain information files that relate to commercial documents such as invoice, receipts and business contacts (Data Interchange Plc, 2006).

The essential elements of EDI include direct application-to-application communication, the use of an electronic transmission medium, use of electronic mail boxes for storage and collection, storage and transmission of documents and use of structured, formatted messages based upon internationally agreed standards. However, implementation of EDI may be faced by a number of challenges. Such challenges include: difficulty of understanding its importance making organizations fear implementing it and technical problems associated with its implementation. It is important to note that implementation of EDI calls for total commitment and support from the top management (Swatman and Swatman, 1991). Data Interchange Plc (2006) points out that a logical EDI code should be a computer application, a trading sub division of a company, a company or a collection of organizations. EDI routing takes three levels; physical routing concerned with communication with other systems, file routing that allows interchange of files and interchange routing that controls interchange between segments in the system.

Just like ERP, implementation of EDI is an elaborate process that involves a number of stages. The first stage is planning that involves coming up with a proposal on the changes that are to put into place for implementation of EDI and the requirements need for the process. The second stage is analysis and design. A design team should be put into place to conduct analysis on the current situation and recommend changes required for EDI system. The next stage is construction and installation of the system. During this stage, legal and physical considerations need to be put into considerations (Obara et al., 2010).

Performance of EDI is highly dependent on the partnership attributes an organization has. Maunola (2009) conducted a study to establish the effect of partnership attributes on EDI performance. He considered three attributes; partner trust, partner interdependence and partner commitment. The study revealed that these attributes enhance integration, utilization and diversity enhancing EDI implementation success and thereby enhancing EDI performance. He came up with the following diagrammatic presentation on the relationship shown in figure 2.2 .

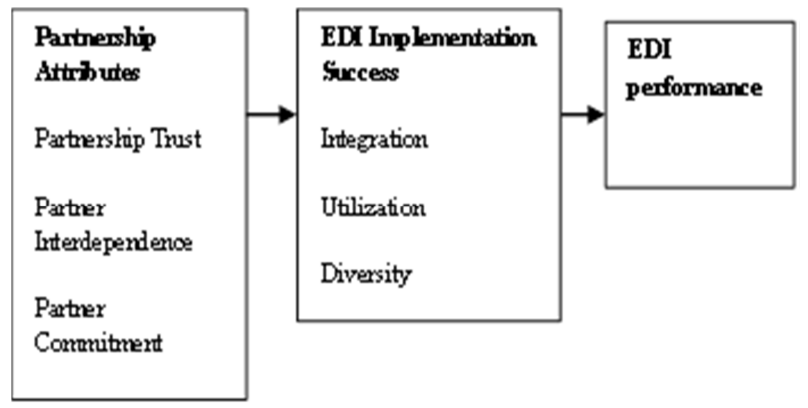

Source: Maunola (2009).

Figure 2.2. Effect of Parnership Attributes on EDI Performance.

\subsection{Upstream Supply Chain Management}

Christopher (1998) defines Supply Chain Management as the management of upstream and downstream relationships with suppliers and customers to deliver superior customer value most economically while ensuring high operational performance in the entire supply chain. It casts manufacturers in the role of customer and drive the supply chain initiative upstream the supply chain. It allows manufacturers to leverage the standards and other infrastructure already in place for customers and introduces standards at the source of supply chains, for use by all trading partners to the end consumer. Upstream supply chain management also is about identifying savings and improvements for both manufacturers \& suppliers.

GSI (2008) developed an upstream integration model for supply chain and stated that the model is based on a number of building blocks: procurement that is composed of integration agreement, master data alignment and purchase conditions, material forecasting which is based on demand and supply signals, inventory management and traceability based on dispatch receipt and consumption and financial settlement. The blocks enable the system to support a collaborative approach for: supplier initiated ordering and manufacturer initiated ordering. This model is associated with benefits such as: reduced inventory levels, reduced administration cost, reduced lead times, reduced production costs and improved service level to customers. A linear supply chain model capture upstream supply chain on the left hand side of the model as shown in figure 2.3

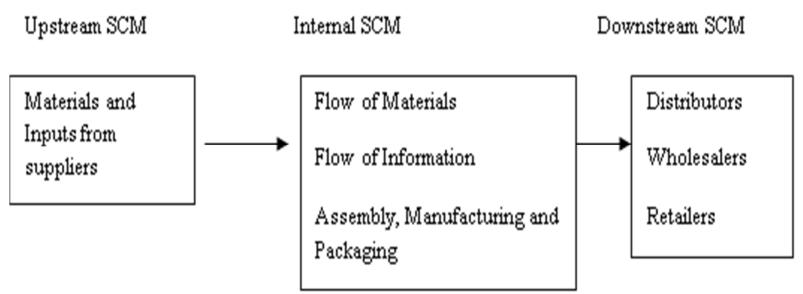

Figure 2.3. A Linear Supply Chain Model. Source: Dell.com.

\subsection{Empirical Literature}

A study conducted by Buxmann et al (2004) found out that 
not many organizations already implement well-structured supply chain management software. However, the ones that are already using the supply chain management software enjoy improvements in cooperation, supply chain redesign, as well as supplier evaluation and selection are even harder to quantify. They also concluded that the implementation of Supply Chain Management Software involves expensive alterations and customizations in the organization and therefore organizations have to be strategic in adopting these systems. They further suggested further research on the potential benefits and problems of using supply chain management software.

Gunasekaran (2004), in his study on Information Systems in supply chain integration and management found out that the strategic information systems should include the strategic objectives of supply chain management the information systems architecture should be designed for SCM different from that of traditional organizations. It is important to note that successful strategic information systems are not easy to implement in SCM and they require major changes in how a business operates internally and with external partner. The existing commercial enterprise information systems require flexibility in the organization operations so as to accommodate individual organizational characteristics. Every organization that adopts a new SCM system must establish performance measures and metrics for measuring the performance and suitability of the system in SCM. It is also crucial to develop standards and legal frameworks for the application of SCM software. Lastly, there must be an alignment between information model and supply chain model.

Giménez and Lourenço (2005) in his study one supply chain management found out that use of the internet in managing supply chain management can improve the competitiveness of organizations. He looked at e supply chain management, e-procurement, e-commerce and ecollaboration. They observed that through these operations; organizations can enhance their supply chain operations especially the upstream supply chain operations. Done, (2011) also pointed out that use of internet enhances efficiency of information transfer, timeliness of information availability, relevance of business information, openness and transparency in the supply chain.

Hill and Scudder (2002) conducted a study on the use of electronic data interchange for supply chain coordination in the food industry and revealed that EDI is instrumental in inter-organizational transfer of supply chain data. Transfer of such information is important in performance of upstream supply chain. Use of EDI is associated with enhanced coordination of suppliers to the organization and coordination of customers to the organization. This study suggested further research to consider organizational characteristics in establishing the relationship between EDI and supply chain performance.

Umble (2003) conducted a study on enterprise resource planning: implementation procedures and critical success factors. This study appreciated the complex nature of ERP systems. He pointed out that implementation of ERP is costly and demands a lot of organizational time and resources. Fui-Hoonnah and Delgado (2006) sought to establish the critical factors in the implementation of ERP and identified seven factors; business plan and vision, change management, communication, ERP team composition, skills and compensation, management support and championship, project management skills, system analysis, selection and technical implementation skills.

\subsection{Conceptual Framework}

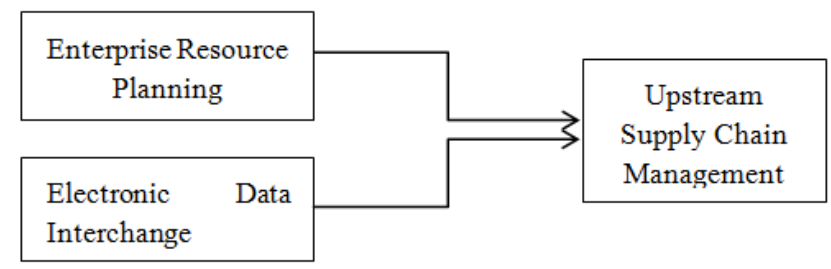

Figure 2.4. Conceptual Framework.

\section{Research Methodology}

As Oso and Onen (2011) points out, the research design adopted by the researcher should answer the questions the study is seeking to answer or the objectives the researcher seeks to achieve by conducting the study. According to Sukaran (2010), correlational design involves delineation of the important variables associated with the research problem and investigates one or more characteristics of a group to discover the extent to which the characteristics vary together. This was a correlational cross sectional survey where data will be collected at single point in time.

Oso and Onen (2011) define the target population as the total number of subjects targeted by the study or the group of elements to which the researcher wants to make inference. In this study, the population elements were the employees in the procurement and Information Technology departments in the nine supermarkets in Nakuru town. The sample was purposefully selected to include head of procurement department and head of information technology department from every supermarket.

Primary data was collected using self-structured questionnaire. The questionnaires were designed to collect data on Enterprise Resource Planning and Electronic Data Interchange. Since the data collected was qualitative, five-point likert scale was used to capture the required information. Regression analysis was conducted to establish the effect of Enterprise Resource Planning Electronic Data Interchange on upstream supply chain management.

\section{Findings, Conclusions and Recommendations}

\subsection{Regression Analysis}

Regression analysis was conducted to test the overall effect 
of information systems on Upstream Supply Chain Management in Nakuru town. The results were as presented in table 4.1 .

Table 4.1. Regression Table.

\begin{tabular}{lllll}
\hline Model & R & R Square & $\begin{array}{l}\text { Adjusted R } \\
\text { Square }\end{array}$ & $\begin{array}{l}\text { Std. Error of the } \\
\text { Estimate }\end{array}$ \\
\hline 1 & $.311 \mathrm{a}$ & .097 & .058 & .751 \\
\multicolumn{2}{l}{ a. Predictors: (Constant), ERP, EDI } & & \\
\hline
\end{tabular}

From table 4.1, $\mathrm{R}$ square is extent to which ERP and EDI affect Upstream Supply Chain Management of supermarkets. $\mathrm{R}$ square $=0.097$ reveals that information systems have overall prediction of $9.7 \%$ on Upstream Supply Chain Management in Nakuru town.

\subsection{ANOVA Test}

ANOVA test was conducted to test the statistical significance of the overall effect of information systems on Upstream Supply Chain Management in Nakuru town. The results were as presented in table 4.2.

Table 4.2. ANOVA Table.

\begin{tabular}{|c|c|c|c|c|c|c|}
\hline \multicolumn{2}{|c|}{ Model } & \multirow{2}{*}{$\begin{array}{l}\begin{array}{l}\text { Sum of } \\
\text { Squares }\end{array} \\
2.842\end{array}$} & \multirow{2}{*}{$\frac{\text { df }}{2}$} & \multirow{2}{*}{$\begin{array}{l}\text { Mean } \\
\text { Square }\end{array}$} & \multirow{2}{*}{$\begin{array}{l}\mathbf{F} \\
2.517\end{array}$} & \multirow{2}{*}{$\begin{array}{c}\text { Sig. } \\
.000^{\mathrm{a}}\end{array}$} \\
\hline & Regression & & & & & \\
\hline \multirow[t]{2}{*}{1} & Residual & 26.538 & 47 & .565 & & \\
\hline & Total & 29.380 & 49 & & & \\
\hline \multicolumn{7}{|c|}{ a. Predictors: (Constant), ERP. EDI } \\
\hline \multicolumn{7}{|c|}{ b. Dependent Variable: Upstream Supply Chain Management } \\
\hline
\end{tabular}

The significance value of $0.000(<0.05)$ implies that in overall, information systems have statistically significant effect on Upstream Supply Chain Management of Supermarkets in Nakuru County. It can therefore be concluded that information systems has statistically significant effect on Upstream Supply Chain Management.

\subsection{Table of Coefficients}

The coefficients of the indicators were obtained as presented in table 4.3

Table 4.3. Table of Coefficients.

\begin{tabular}{|c|c|c|c|c|c|c|}
\hline \multirow{2}{*}{\multicolumn{2}{|c|}{ Model }} & \multicolumn{2}{|c|}{$\begin{array}{l}\text { Unstandardized } \\
\text { Coefficients }\end{array}$} & \multirow{2}{*}{$\begin{array}{l}\text { Standardized } \\
\text { Coefficients } \\
\text { Beta } \\
\end{array}$} & \multirow[t]{2}{*}{$-\mathbf{t}$} & \multirow[t]{2}{*}{ Sig. } \\
\hline & & B & Std. Error & & & \\
\hline \multirow{3}{*}{1} & (Constant) & 2.839 & .729 & & 3.897 & .000 \\
\hline & ERP & -.032 & .149 & -.030 & -.213 & .832 \\
\hline & EDI & .307 & .137 & .311 & 2.242 & .030 \\
\hline \multicolumn{7}{|c|}{ a. Dependent Variable: Upstream Supply Chain Management } \\
\hline
\end{tabular}

The first hypothesis was Ho1: Enterprise Resource Planning has no significant effect on Upstream Supply Chain Management of supermarkets in Nakuru town. The $\mathrm{t}=-213$ and $\mathrm{p}=0.832(>0.05)$ reveal that ERP has insignificant negative effect on Upstream Supply Chain Management of supermarkets in Nakuru town. The first hypothesis is therefore not rejected and conclusion made that ERP has insignificant negative affect on Upstream Supply Chain Management of supermarkets in Nakuru town

The second hypothesis was Ho2: EDI has no significant effect on Upstream Supply Chain Management of supermarkets in Nakuru town. The $\mathrm{t}=2.242$ and $\mathrm{p}=0.030$ $(<0.05)$ reveal that EDI has statistically significant positive effect on Upstream Supply Chain Management of supermarkets in Nakuru town. The second hypothesis was therefore rejected and it is concluded that EDI has significant positive effect on Upstream Supply Chain Management of supermarkets in Nakuru town.

From the research findings, it was concluded that ERP has statistically insignificant effect on Upstream Supply Chain Management of supermarkets in Nakuru town. On the other hand, the study revealed that EDI has significant positive effect on Upstream Supply Chain Management of supermarkets in Nakuru town. The study therefore recommends that organizations, especially fast moving inventory take a strategic approach to adoption of information systems concerned with supply chain management. It is important that such organizations consider the contribution of the systems before deciding on which information system to adopt as these systems are resource intensive to put into place.

\section{References}

[1] Buxmann, P., Ahsen, A., Díaz, L. M. \& Wolf, K. (2004). Usage and evaluation of Supply Chain Management Software results of an empirical study in the European automotive industry. Info Systems J 14, 295-309

[2] Christopher, M. (1998). Logistics and Supply Chain Management: Strategies for reducing cost and improving service. London, Financial Times Pitman Publishing.

[3] Giméneze, C. and Lourenço, H. R. (2005). E-Supply Chain Management: review, implications and directions for future research.

[4] Gunasekaran, A. (2004). Information Systems in Supply Chain Integration and Management. European Journal of Operational Research 159 (2004) 269-295

[5] Motwani, J., Madan, M., Gunasekaran, A., 2000. Information Technology in Managing Supply chains. Logistics Information Management 13 (5), 320-327.

[6] Nemati A., S. and Mangaladurai, D. (2013). Impact of Enterprise Resource Planning in Supply Chain Management. University College of Borås http://www.dell.com. Viewed on $19^{\text {th }}$ April, 2014.

[7] Toke, L.K., Gupta, R.C. and Dandekar, M. (2012). An empirical study of green supply chain management in Indian perspective. Int. Journal of Applied Sciences and Engineering Research 1(2)372-383.

[8] Ron Fricker (2012). Target Populations, Sampling, Frames, and Coverage Error. Naval Postgraduate School Monterey, California. 
[9] Umble, E. J., Haft, R. R. and Umble, M. M. (2003). Enterprise resource planning: Implementation procedures and critical success factors. European Journal of Operational Research 146 (2003)241-25.

[10] Fui-Hoonnah, F. and Delgado, S. (2006). Critical Success Factors for Enterprise Resource Planning Implementation and Upgrade.

[11] OíLeary, D. E. (2004). Enterprise Resource Planning (ERP) Systems: An Empirical Analysis of Benefits. Journal of Emerging Technologies in Accounting 1, 63-72.

[12] Data Interchange Plc, (2006). Electronic Data Interchange.

[13] Hill, C. A. and Scudder, G. D. (2002). The use of electronic data interchanges for supply chain coordination in the food industry. Journal of Operations Management 20, 375-387.
[14] Morell, A. J., Neal, W. and Fries, V. (1995). Promoting Electronic Data Interchange: Building a Foundation for Support to Small Business. Industrial Technology Institute.

[15] Obara, P. M., Kiplagat, L. J. and Okidi, A. N. (2010). The Benefits and Challenges of Electronic Data Interchange. Implementation and Application at Kilindini Water Front Project in Kenya. African Journal of Business \& Managemen, 1, 212-236.

[16] Maunola, (2009). The Impact of Electronic DataInterchange and E-Invoicing on Buyer-Seller Relationships in Business-To-Business Markets. Information Systems Science Master's thesis. Department of Business Technology, Helsinki School Of Economics.

[17] PADIS (2014). Adoption of Accounting Information Systems in Organization in Africa. University Of Pennsylvania African Studies Center. 